\title{
Protection of Metal Surfaces from Microbial Colonization
}

\author{
Rawia Mansour ${ }^{1}$ and Ali Mohamed Elshafei ${ }^{2^{*}}$ \\ ${ }^{1}$ Egyptian Petroleum Research Institute (EPRI), 1 Elzhoor Region, Box:11727, Cairo, Egypt. \\ ${ }^{2}$ Department of Microbial Chemistry, National Research Centre, 33 El Bohouth St. (Former \\ El Tahrir St.), Dokki, Giza, P.O.Box: 12622, Egypt.
}

Authors' contributions

This work was carried out in collaboration between the two authors. Author RM designed the study, wrote the protocol and wrote the first draft of the manuscript. Author AME managed the literature searches. Both authors read and approved the final manuscript.

Article Information

DOI: $10.9734 / A R R B / 2017 / 34452$

Editor(s):

(1) Ram Pratap Yadav, Department of Zoology, DDU, Gorakhpur University, Gorakhpur (U.P.)-273009, India.

(2) George Perry, University of Texas at San Antonio, USA.

Reviewers:

(1) Mahima Srivastava, H.N.B. Garhwal University, Uttarakhand, India.

(2) Omega M. Immanuel, University of Port Harcourt, Nigeria.

(3) Iram Liaqat, GC University, Lahore, Pakistan.

Complete Peer review History: http://www.sciencedomain.org/review-history/19847

Review Article

Received $28^{\text {th }}$ May 2017

Accepted $29^{\text {th }}$ June 2017

Published $4^{\text {th }}$ July 2017

\begin{abstract}
This review discusses some aspects relating to the microbial interaction to metal surfaces. Most of the previous studies assumed that this process results in increased corrosion rates (MIC), however more recently it has been reported that many bacterial species can reduce corrosion rates of different metals and alloys in many corrosive environments by changing drastically the electrochemical conditions at the metal-solution interface. These changes ranged from acceleration of corrosion to corrosion inhibition. Microorganisms can contribute to corrosion inhibition by different means such as neutralizing the action of corrosive substances, formation of protective films on a metal surface and finally through the induction of a decrease in the medium corrosiveness. The mechanism of corrosion protection seems to be different for different bacteria since it has been found that the corrosion potential $E_{\text {corr }}$ became more negative in the presence of Shewanella ana and algae, but more positive in the presence of Bacillus subtilis. We previously described the efficient effect of the prepared 1,3-Bis-(4-amino-benzoyl) thiourea (AB-T) compound on corrosion
\end{abstract}


inhibition of carbon steel in $0.5 \mathrm{M}$ hydrochloric acid solution using different concentrations and different methods. In addition, results obtained indicated that AB-T was found to possess an antimicrobial activity against Gram-positive bacteria (Bacillus mycoides), Gram-negative bacteria (Escherichia coli) and non-filamentous fungi (Candida albicans).

Keywords: Biocorrosion; biofilms · corrosion inhibition; protection of surfaces; biocides.

\section{INTRODUCTION}

Generally application of antimicrobial surfaces is very important in our setting at home, industry and clinics. These antimicrobial surfaces have the ability to stop, reduce the propagation of microorganisms on different surfaces [1]. The medical sector comprises the most important use of antimicrobial coating for sterilization of medical devices in order to prevent the hospital associated infections [2]. The applications of antimicrobial coating to surfaces may be functionalized either by the presence of a toxic chemical to infectious microorganisms or by the attachment of a polymer or a polypeptide to the treated surface. The discovery of intrinsic properties of copper [3-5] and its alloys (such as copper-nickel-zinc) [6] to stop the detrimental effect of a wide range of microorganisms including Methicillin Resistant Staphylococcus aureus (MRSA) [7,8], Escherichia coli [9,10], Clostridium difficile $[11,12]$, adenovirus and fungi represent an innovation in antimicrobial surfaces applications $[13,14]$. The process of interaction between bacteria and metal surfaces resulting in the formation of biofilms represents one of the major problems inducing the formation of MIC. The formation of a well developed bacterial biofilm on many medical devices such as catheter represents one of the major problems in health risk in urinary tract infections in hospitals [15]. Biofilm formation starts by the attachment of floating microorganisms to a surface, followed by the formation of extracellular polymeric substances (EPS) by them. A fully developed biofilm contains many layers including a matrix of EPS with vertical structures protect bacteria and let them more resistant to traditional antimicrobial treatments. The spaces between the vertical biofilm structure allow the bulk of the biofilm to easily take in nutrients from the surrounding liquid and move byproducts away from the biofilm [16]. The formation of a biofilms are rather complex process but can be summarized in four steps namely deposition of the conditioning film, attachment of microorganisms to the conditioning film, propagation and bacterial colonization and finally biofilm formation [17]. Investigators reported that more hydrophobic materials and rougher surfaces will develop biofilms faster besides the unique microbial cell properties and structure such as pilli, flagella and fimbriae [18].

\section{MECHANISMS OF ANTIMICROBIAL AGENTS}

The mode of action of many antimicrobial agents has been studied for decades and is still under investigation. Silver ions have been shown to inhibit oxidative enzymes (such as alcohol dehydrogenase) in yeast strains by reaction with the thiol group of enzymes leading to their inactivation [19]. In addition, silver ions have been shown to interact with DNA to enhance pyrimidine dimerization and probably prevent DNA replication [20]. The most probable mechanisms for the action of copper as antimicrobial agent are summarized as follows: a) The presence of high level of copper within the cell causes oxidative stress and production of $\mathrm{H}_{2} \mathrm{O}_{2}$, under the reaction condition an oxidative damage occurs to cells (Fenton-type reaction) [21]. b) Copper causes deterioration in membranes integrity of microorganisms. This leads to a decrease in essential nutrients uptake (such as potassium) and consequently leading to cell death. c) In some cases copper improperly binds with proteins in reactions that do not need copper for their function. This leads to loss of function of protein. The antimicrobial effect of organosilanes of the nano-type depends on the disruption of the outer membranes of the microbes attempting to reach the surface and this means the failure of microorganisms to colonize. This type of coating can be applied to hard and soft surfaces. Many investigators proposed a mixed coating of organosilanes with quaternary ammonium salts to ensure fast microbial kill and permanent antimicrobial coating. Quaternary ammonium compounds have been found to have antimicrobial activity when covalently attached to surfaces. In this connection, alkyl-dimethyl-benzyl ammonium chloride was found to form a double monolayer coverage of Staphylococcus aureus cells, while didecyl-dimethyl ammonium chloride forms a single monolayer $[22,23]$. This action leads to bacterial cell leakage and release of cell 
components causing cell death. Guan [24] reported that $100 \%$ solids polyurethane system and substrate surfaces coated with the modified coating show high percentage of reduction of microorganisms in water and wastewater systems.

\section{SELECTIVITY OF ANTIMICROBIAL COATINGS AGAINST MICROBES}

As we previously mentioned that silver and silver alloys coatings are very efficient in preventing the growth and propagation of bacteria especially against MRSA, Staphylococcus aureus, Pseudomonas aeruginosa and Escherichia coli. The most important action to stop the colonization of bacteria to surfaces is made by preventing the initial adhesion of bacterial cells to surfaces either by some compounds such as chlorohexidine or antibiotics such as vancomycin, amoxicillin or tobramycin [25]. The protection of surfaces against viruses attack plays a major role in cutting down on the spread of a virus. Painting of glass slide surfaces with hydrophobic poly-cation $\mathrm{N}, \mathrm{N}$ dodecyl- methylpoly-ethylenimine is found to be lethal to waterborne influenza A viruses. The transmission of viruses occur when a patient touches respiratory droplets settled on an infected surfaces or transmitted from person to person through airborne droplet during coughing or sneezing $[26,27]$. The application of copper alloy to surfaces reduces about $75 \%$ of active influenza A particles after only one hour of incubation [1]. Concerning antifungal activity, copper and its alloys surfaces are found to be effective against the spores of different filamentous fungi namely Aspergillus niger, Penicillium chrysogenum and non-filamentous fungus Candida albicans [6]. Other investigators reported that when chromogranine peptide is included in the surface resulted to the inhibition of fungal growth by interfering with fungal membrane penetrating fungal cell [28]. This antifungal peptide coating has an inhibition effect against the growth of Candida albicans. We previously described the effect of the prepared 1,3-Bis-(4-amino-benzoyl) thiourea (AB-T) compound on corrosion inhibition of carbon steel in $0.5 \mathrm{M}$ hydrochloric acid solution using different methods including potentiodynamic polarization, weight loss at different inhibitor concentrations, electrochemical methods as open circuit potential (OCP) and electrochemical impedance spectroscopy (EIS) [29]. Results obtained indicated that $\mathrm{AB}-\mathrm{T}$ inhibition efficiencies provide $32 \%, 38 \%, 60 \%, 73 \%, 76 \%$ and $84 \%$ at 40,60 ,
$80,100,200$ and 300 ppm respectively. On the other hand, at higher inhibitor concentrations (400 and 500 ppm) a detectable decrease in inhibition efficiency was noticed $(47 \%$ and $28 \%$ respectively). The corrosion potential in open circuit and EIS at low inhibitor concentrations were shifted toward positive direction (i.e., cathodic protection), however at high inhibition concentrations potentials were shifted toward negative direction (i.e., anodic protection). The electrochemical impedance results indicate that the inhibition efficiency increased with the increase of inhibitor concentration. We also concluded that $A B-T$ possess not only high anticorrosion properties but also an anti-microbial activity against Gram-positive bacteria (Bacillus mycoides), Gram-negative bacteria (Escherichia coli) and non-filamentous fungi (Candida albicans) [29]. Zhong et al. [30] demonstrated the antimicrobial behaviors of acyl thiourea derivatives of chitosan against four species of bacteria and four crop threatening fungi. They found that all the acyl thiourea derivatives had a significant inhibitory effect and the antifungal activities of the chloracetyl thiourea derivatives of chitosan are noticeably higher than the acetyl and benzoyl thiourea derivatives [30]. Chen et al. [31] prepared and characterized thiourea chitosan $\mathrm{Ag}^{+}$complex using different methods and the antimicrobial activities of the complex was evaluated against six species of bacteria and molds. The complex showed a wide spectrum of antimicrobial activities and has a better antibacterial activity than antifungal one in agreement of the results obtained by Mansour [29].

\section{BENEFICIAL BIOFILMS}

A microbial biofilm is an assemblage of surfaceassociated microbial cells that is enclosed in an extracellular polymeric substance (EPS) matrix. EPS may account for 50 to $90 \%$ of the total organic carbon of biofilm and is considered the primary matrix material of a biofilm which composed mainly of polysaccharides [32]. Some of these polysaccharides are neutral or polyanionic as in case of Gram-negative bacteria. The presence of uronic acids (such as D-glucuronic, D-galacturonic, and mannuronic acids) confers the anionic property [33]. The chemical composition of EPS may be quite different and may be primarily cationic in case of some Gram-positive bacteria such as Staphylococci. Many investigators reported that that the slime of coagulase Gram-negative bacteria consists of a teichoic acid mixed with 
proteins [34]. In the literature many investigators reported that biofilms have beneficial uses as well as harmful impacts. Microorganisms make up the majority of the living biomass on Earth. While some bacteria produce effects that are bad for other organisms, most bacteria are harmless or even beneficial [35]. Generally beneficial biofilms participate by a way or another to the welfare of our life [36], for example many biofilms play a major role in the ecology of the earth and sustainability of life in general, besides biofilms have important role in the recycling of elements vital to life $[37,38]$. Another beneficial application of biofilms is to solve problem in the treatment of wastewater by passing this contaminated water through a biofilm resulting in the removal of harmful and toxic organic materials from the water. In this connection scientists indicated that drinking water and wastewater that have been processed with a biofilm system in a treatment plant are more biologically stable than water filtered by other types of treatment systems [39]. One of the less important beneficial applications of biofilms is in the remediation of contaminated soil and groundwater with oil and gasoline [40]. Bioremediation using engineered biofilms has emerged as a technology of choice for cleaning up groundwater and soil at many location contaminated with toxic wastes, Microbial leaching with the assistance of microbial biofilms is very important task for recovering many metals by oxidation of the insoluble ore particles of these metals [41]. Thus Thiobacillus attached to the ore particles oxidize the insoluble copper compounds to soluble copper sulfate from which the pure copper can be obtained. The chemical composition of biofilm is shown in Table 1 [42].

\section{Table 1. Biofilm chemical composition}

\begin{tabular}{ll}
\hline Component & Percentage of matrix \\
\hline Microbial cells & $2-5 \%$ \\
DNA and RNA & $<1-2 \%$ \\
Proteins \& enzymes & $<1-2 \%$ \\
Polysaccharides & $<1-2 \%$ \\
Water & Up to $97 \%$ \\
\hline
\end{tabular}

\section{FACTORS AFFECTING MICROBE'S COLONIZATION ON SURFACES}

The topology of any surface determines the possibility of microorganisms especially bacteria to colonize on surfaces. Fluorocarbons are excellent substrate compounds to perform the super-hydrophobic surfaces due their low surface energy [43]. Textiles surfaces were found to be easily penetrated by microbes due to the presence of spaces between fibers [8]. Grafting of functionalized polymers is another possible way to impart antimicrobial properties to surfaces. This process is typically achieved through a coupling agent that links a handle on the surface to a reactive group. Recently many nanoparticles compounds have been applied to surfaces to impart antimicrobial properties due to their unique behavior namely silver, gold, titanium dioxide, copper, gallium and organosilane [5].

\section{INTERACTION OF BACTERIA AND METAL SURFACES}

Generally the major interaction reaction of bacteria and metal surfaces resulted to an increase in corrosion a rate which is called microbiology influenced corrosion (MIC), by this procedure the metal is dissolved under the area of microbial deposits producing a pit [44]. However, some specified beneficial bacteria exert their protective effect against corrosion through the formation of biofilms or producing a sticky protective layer [45].

\subsection{Microbiology Influenced Corrosion (MIC)}

Biofouling is the process of interaction between bacteria and metal surfaces resulting in the formation of biofilms. One of the early studies indicated that sulphate reducing bacteria (SRB), are the main cause of MIC of carbon steels [46]. These bacteria thrive only in an anaerobic atmosphere and widespread in many soils and waters. In the cathodic depolarization mechanism, SRB remove atomic hydrogen from iron surface and consequently accelerate the corrosion of iron. The Ennoblement or the increase of the open-circuit potential $E_{\text {corr }}$ due to the formation of a biofilm has been observed in stainless steel exposed to natural seawater [47]. In this connection, when Little and Mansfeld [48], exposed polymer coated steel samples with intentional defects to natural seawater they observed that a large number of bacteria were present on the rust layers of samples that were exposed at their natural $E_{\text {corr }}$ while no bacteria were found for samples that were cathodically protected by connection to a piece of zinc. 
$\mathrm{SO}_{4}^{-2}+\underset{\mathrm{H}}{2}$
Cathodic depolarization

\subsection{MIC Inhibition}

The possibility of corrosion inhibition caused by microorganisms has rarely been considered. Corrosion inhibition due to the formation of biofilms has been observed for different materials exposed to corrosive environments in the presence of different bacteria [49-51]. Generally, corrosion-inhibitors performed their action when they incorporated in small amounts to a given environment resulting to a decrease in the rate of attack by this environment on a metal. Microorganisms can change drastically the electrochemical conditions at the metal-solution interface. These changes ranged from acceleration of corrosion to corrosion inhibition. The enhancement of corrosion by microorganisms includes the stimulation of the anodic reaction by acidic metabolites or by the cathodic reaction through the microbial formation of new alternative cathodic reactants such as $\mathrm{H}_{2} \mathrm{~S}$. Microbial effects causing corrosion inhibition have been rarely mentioned in the literature. Microorganisms can contribute to corrosion inhibition by different mechanisms; the first mechanism includes neutralizing the action of corrosive substances present in the environment, the second through the formation of protective films or stabilizing a pre-existing protective film on a metal. The third mechanism through the induction of a decrease in the medium corrosiveness. The microbial inhibition of corrosion and its counter-process MIC inhibitions are rarely linked to a single species of microorganisms or to a single mechanism. The main mechanisms of bacterial corrosion inhibition are always linked to a marked modification of the environmental conditions at the metal-solution interface due to biological activity. The positive features of microbial corrosion inhibition can be summarized through a decrease in the cathodic rate by microbial consumption of a cathodic reactant, decreasing the medium aggressiveness by neutralizing acidity and stabilizing protective films on the metal surface [49,52]. Mansfeld [41], described the inhibition of pitting in the presence of $B$. subtilis by the exclusion of oxygen from the metal surface which would reduce the rate of cathodic reduction reaction leading to an increase of $E_{\text {corr }}$ below $E_{\text {pit }}$ when a bacterium having the ability to reduce poisonus heavy metal ions and can live with or without oxygen namely Shewanella oneidensis MR-1 was added to a cell containing Al 2024 and $\mathrm{Cu}$ in a growth medium.
He also reported that many bacteria including certain strains of Shewanella can prevent pitting of Al 2024 in artificial seawater and rusting of mild steel and reduce corrosion rates of different metals and alloys in many corrosive environments. MIC inhibition is not often linked to a single mechanism or to a single species of microorganisms. The formation of microbial biofilms mediate the interactions between metal surfaces and the liquid environment, leading to modifications of the metal-solution interface by drastically changing the types and concentrations of ions, $\mathrm{pH}$, and oxygen levels.

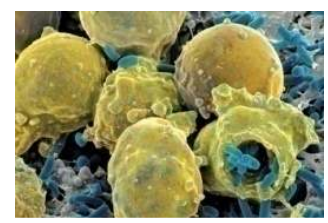

Microbial Biofilms------------ $\rightarrow$ Surface Protection

\section{CONCLUSION}

Hospital trials indicated that copper surfaces are a promising tool to decrease the number and severity of hospital-acquired infections besides many other antimicrobial coatings. Microbiology induced corrosion is rarely linked to a single mechanism or to a single species of microorganisms. The formation of biofilms mediate the interactions between metal surfaces and the surrounding liquid environment resulting to major modifications of the metal-solution interface. By these major changes the electrochemical behavior of the metal can be modified from active to passive and a microbial inhibition of corrosion can be obtained. The next new trends in research should focus on bioelectrochemical phenomena at the metal surface, the development of monitoring devices, and methods to control microbial deleterious effects.

\section{ACKNOWLEDGEMENT}

Authors acknowledge the support provided by the Egyptian Petroleum Research Institute (EPRI) and the National Research Centre (NRC), Egypt.

\section{COMPETING INTERESTS}

Authors have declared that no competing interests exist. 


\section{REFERENCES}

1. Kusumaningrum HD, Riboldi G, Hazeleger WC, Beumer RR. Survival of foodborne pathogens on stainless steel surfaces and cross-contamination to foods. Int. J. Food Microbiol. 2003;85:227-236.

2. Espirito Santo C, Morais PV, Grass G. Isolation and characterization of bacteria resistant to metallic copper surfaces. Appl. Environ. Microbiol. 2010;76:1341-1348.

3. Airey P, Verran J. Potential use of copper as a hygienic surface; problems associated with cumulative soiling and cleaning. J. Hosp. Infect. 2007;67:272-278.

4. Balasubramanian $R$, Rosenzweig $A C$. Copper methanobactin: A molecule whose time has come. Curr. Opin. Chem. Biol. 2008;12:245-249.

5. Casey AL, Adams D, Karpanen TJ, et al. Role of copper in reducing hospital environment contamination. J. Hosp. Infect. 2010;74:72-77.

6. Mehtar S, Wiid I, Todorov SD. The antimicrobial activity of copper and copper alloys against nosocomial pathogens and Mycobacterium tuberculosis isolated from healthcare facilities in the Western Cape: An in-vitro study. J. Hosp. Infect. 2008;68:45-51.

7. Dancer SJ. Importance of the environment in meticillin-resistant Staphylococcus aureus acquisition: The case for hospital cleaning. Lancet Infect. Dis. 2008;8:101113.

8. Michels HT, Noyce JO, Keevil CW. Effects of temperature and humidity on the efficacy of methicillin-resistant Staphylococcus aureus challenged antimicrobial materials containing silver and copper. Lett. Appl. Microbiol. 2009;49:191-195.

9. Rouch D, Camakaris J, Lee BT, Luke RK. Inducible plasmid-mediated copper resistance in Escherichia coli. J. Gen. Microbiol. 1985;131:939-943.

10. Wilks SA, Michels $\mathrm{H}$, Keevil CW. The survival of Escherichia coli 0157 on a range of metal surfaces. Int. J. Food Microbiol. 2005;105:445-454.

11. Weaver L, Michels HT, Keevil CW. Survival of Clostridium difficile on copper and steel: Futuristic options for hospital hygiene. J. Hosp. Infect. 2008;68:145-151.

12. Wheeldon LJ, et al. Antimicrobial efficacy of copper surfaces against spores and vegetative cells of Clostridium difficile: The germination theory. J. Antimicrob. Chemother. 2008;62:522-525.

13. Noyce JO, Michels $\mathrm{H}$, Keevil CW. Inactivation of influenza A virus on copper versus stainless steel surfaces. Appl. Environ. Microbiol. 2007;73:2748-2750.

14. Weaver L, Michels HT, Keevil CW. Potential for preventing spread of fungi in air-conditioning systems constructed using copper instead of aluminium. Lett. Appl. Microbiol. 2010;50:18-23.

15. Dror N, Mandel M, Hazan Z, Lavie G. Advances in microbial biofilm prevention on indwelling medical devices with emphasis on usage of acoustic energy. Sensors. 2009;9(4):2538-2554.

DOI:10.3390/s90402538.

Available:http://www.mdpi.com/14248220/9/4/2538/

16. Secinti DK, Özalp H, Attar A, Sargon FM. Nanoparticle silver ion coatings inhibit biofilm formation on titanium implants. Journal of Clinical Neuroscience. 2011;18(1):391-395.

DOI:10.1016/i.jocn.2010.06.022

17. Lennox J. Biofilm development. Biofilms: The Hypertextbook. Web; 2011.

$<$ http://biofilmbook.

18. Donlan Rodney M. Biofilm formation: A clinically relevant microbiological process. Clinical Infectious Diseases. 2001;33(8): 1387-392. Chen S, Wu G, Zeng $\mathrm{H}$. Preparation of high antimicrobial activity thiourea chitosan- $\mathrm{Ag}^{+}$complex. Carbohydrate Polymers. 2005;60(1):3338.

19. Macomber L, Imlay JA. The iron-sulfur clusters of dehydratases are primary intracellular targets of copper toxicity. Proc. Natl. Acad. Sci. USA. 2009;106:8344-8349.

20. Warnes SL, Green SM, Michels HT, Keevil CW. Biocidal efficacy of copper alloys against pathogenic enterococci involves degradation of genomic and plasmid DNA. Appl. Environ. Microbiol. 2010;76:53905401.

21. Jay D, Cuéllar A, Jay EG, García C, Gleason R, Muñoz E. Study of a fenton type reaction: Effect of captopril and chelating reagents. Archives of Biochemistry and Biophysics. 1992;298(2): 740-746.

22. Faundez G, Troncoso M, Navarrete $P$, Figueroa G. Antimicrobial activity of 
copper surfaces against suspensions of Salmonella enterica and Campylobacter jejuni. BMC Microbiol. 2004;4:19.

23. Karlin KD. Metalloenzymes, structural motifs, and inorganic models. Science. 1993;261:701-708.

24. Guan SW. $100 \%$ solids polyurethane coatings technology for corrosion protection in water and wastewater systems. $9^{\text {th }}$ Middle East Corrosion Conference, Mananma, Bahrain; 2001.

25. Kim EH, Rensing C, McEvoy MM. Chaperone-mediated copper handling in the periplasm. Nat. Prod. Rep. 2010;27:711-719.

26. Kramer A, Schwebke I, Kampf G. How long do nosocomial pathogens persist on inanimate surfaces? A systematic review. BMC Infect. Dis. 2006;6:130-138.

27. Kuhn PJ. Doorknobs: A source of nosocomial infection? Copper Development Association, New York, NY; 1983.

28. Marais F, Mehtar S, Chalkley L. Antimicrobial efficacy of copper touch surfaces in reducing environmental bioburden in a South African community healthcare facility. J. Hosp. Infect. 2010;74:80-82.

29. Mansour R. Anticorrosion and antimicrobial properties of newly synthesized 1,3-Bis-(4-amino-benzoyl) thiourea. Egypt. J. of Appl. Sci. 2008;23(10A):153-168.

30. Zhong Z, Xing R, Lui S, Wang L, Cai S, Li $P$. Synthesis of acyl thiourea derivatives of chitosan and their antimicrobial activities in vitro. Carbohydrate Research. 2008;343(3):566- 570.

31. Chen SP, Wu GZ, Zeng HY. Preparation of high antimicrobial activity thiourea chitosan-Ag + complex. Carbohydr. Polym. 2005;60:33-38.

32. Flemming $\mathrm{HC}$, Wingender $\mathrm{J}$ Griegbe, Mayer C. Physico-chemical properties of biofilms. In: Evans LV, editor. Biofilms: Recent advances in their study and control. Amsterdam: Harwood Academic Publishers. 2000;19-34.

33. Sutherland IW. Biofilm exopolysaccharides: A strong and sticky framework. Microbiology. 2001;147:3-9.

34. Hussain M, Wilcox MH, White PJ. The slime of coagulase-negative staphylococci: Biochemistry and relation to adherence. FEMS Microbiol Rev. 1993;104:191-208. DOI: 10.1111/j.1574-6968.1993.tb05867.x
35. Hall-Stoodley L, Costerton JW, Stoodley P. Bacterial biofilms: From the natural environment to infectious diseases. Nat Rev Microbiol. 2004;2:95-108.

36. Rinaudi LV, Giordano W. An integrated view of biofilm formation in rhizobia. FEMS Microbiol Lett. 2010;304(1):1-11.

DOI: 10.1111/j.1574-6968.2009.01840.x Epub 2009 Oct 30.

37. Morikawa M. Beneficial biofilm formation by industrial bacteria Bacillus subtilis and related species. Journal of Bioscience and Bioengineering. 2006;10(1):1-8.

38. Mary Ellen Davey, George A O'toole. Microbial biofilms: From ecology to molecular genetics. Microbiol Mol Biol Rev. 2000;64(4):847-867.

PMCID: PMC99016

39. Sehar S, Naz I. Role of the biofilms in wastewater treatment. Immunology and Microbiology "Microbial BiofilmsImportance and Applications", book edited by Dharumadurai Dhanasekaran and Nooruddin Thajuddin, ISBN 978-953-512436-8, Print ISBN 978-953-51-2435-1, Published: July 13, 2016.

40. Lear G. Biofilms in bioremediation: Current research and emerging technologies. Book, Publication Date; 2016.

ISBN: 978-1-910190-30-2 DOI:https://doi.org/10.21775/97819101902 $\underline{96}$

41. Bosecker K. Bioleaching: Metal solubilization by microorganisms. FEMS Microbiology Reviews. 1997;20(3-4):591604.

DOI: 10.1111/j.1574-6976.1997.tb00340.x

42. Lu TK, Collins JJ. Dispersing biofilms with engineered enzymatic bacteriophage. PNAS. 2007;104:11197-11202.

43. Molteni C, Abicht HK, Solioz M. Killing of bacteria by copper surfaces involves dissolved copper. Appl. Environ. Microbiol. 2010;76:4099-4101.

44. Miranda E, Bethencourt M, Botana FJ, Cano MJ, Sáchez-Amaya JM, Corzo A, Lomas JG, Fardeau ML, Ollivier B. Biocorrosion of carbon steel alloys by an hydrogenotrophic sulfate-reducing bacterium Desulfovibrio capillatus isolated from Mexican oil field separator. Corrosion Science. 2006;48:2417-2431.

45. Örnek D, Jayaraman A, Syrett BC, Hsu $\mathrm{CH}$, Mansfeld FB, Wood TK. Pitting 
corrosion inhibition of aluminum 2024 by Bacillus biofilms secreting polyaspartate or Y-polyglutamate. Appl Microbiol Biotechnol. 2002;58:651-657.

46. von Wolzogen Kuhr Cah. Unity of anaerobic and aerobic iron corrosion process in the soil. Corrosion $1961 ; 17(6): 293 t-299 t$.

DOI: 10.5006/0010-9312-17.6.119

47. Mansfeld F, Little B. A technical review of electrochemical techniques applied to microbiologically influenced corrosion. Corrosion Science. 1991;32(3):247-272.

48. Little B, Mansfeld F. Proceedings of the $\mathrm{H}$. $\mathrm{H}$. Uhlig Symposium on Passivity of Stainless Steels in Natural Seawater, The Electrochem. Soc. 1994;94(26):42.
49. Mansfeld F. The interaction of bacteria and metal surfaces. Electrochimica Acta. 2007;52:7670-7680.

50. Ornek D, Jayaraman A, Syrett BC, Hsu $\mathrm{CH}$, Mansfeld FB, Wood TK. Pitting corrosion inhibition of aluminum 2024 by Bacillus biofilms secreting polyaspartate or g-polyglutamate. Appl Microbiol Biot. 2002;58:651-657.

51. Ornek D, Jayaraman A, Wood TK, Sun Z, Hsu CH, Mansfeld F. Pitting corrosion control using regenerative biofilms on aluminium 2024 in artificial seawater. Corros. Sci. 2001;43:2121-2133.

52. Videla HA, Herrera LK. Microbiologically influenced corrosion: Looking to the future. International Microbiology. 2005;8:169180.

(C) 2017 Mansour and Elshafei; This is an Open Access article distributed under the terms of the Creative Commons Attribution License (http://creativecommons.org/licenses/by/4.0), which permits unrestricted use, distribution, and reproduction in any medium, provided the original work is properly cited.

Peer-review history:

The peer review history for this paper can be accessed here: http://sciencedomain.org/review-history/19847 